\title{
Ansiedade matemática e gênero no ensino fundamental
}

\author{
Mathematics anxiety and gender in the elementary school
}

\section{Leila do Socorro Rodrigues Feio' Edijane Gomes Borges ${ }^{2}$ Dilene Kátia Costa da Silva ${ }^{3}$}

\begin{abstract}
RESUMO: Este artigo discute ansiedade matemática com estudantes de faixa etária entre seis a nove anos, considerando as suas respostas por gênero. Os dados foram coletados por meio de questionário adaptado do instrumento de Valeski e Stipek (2001). O questinário aplicou-se a vinte e seis estudantes do segundo ano do ensino fundamental, em Santana, município do Estado do Amapá, Brasil. Com base no método estatístico, conforme discutido por Crespo (2002), os resultados foram organizados em frequências relativas e gráficos de linhas construídos no Software Excel. Os estudantes não expressaram ansiedade à matemática ao responder o questionário. Este resultado leva-nos a inferir que, provavelmente, os métodos de ensino de seus professores tornam atrativas as aulas de matemática no ensino fundamental. Além disso, não idetificamos discrepâncias entre as respostas de meninos e meninas, ao questionário que buscou verificar os sentimentos em relação a matemática. Os resultados refletem sobre a importância da família e dos professores incentivarem o desenvolvimento da aprendizagem dos estudantes, pois há diversas situações didáticas e sentimentos presentes no ensino de matemática.

Palavras-chave: Ensino de Matemática, Ansiedade Matemática, Gênero, Ensino Fundamental.
\end{abstract}

ABSTRACT: This paper discusses mathematics anxiety with students aged between six and nine years, considering the answers by gender. Twenty-six students of the second year of the elementary school participated in this study, with age range between six and nine years. The data were collected through a questionnaire adapted from the instrument of Valeski and Stipek (2001). The questionnaire applied to twenty-six students of the second year of elementary school, in Santana, municipality of the State of Amapá. Based on the statistical method, as discussed by Crespo (2002), the results were organized in relative frequencies and line graphs constructed in the Excel Software. Students did not express anxiety to mathematics when they answered the questionnaire. This result leads us to infer that their teachers' teaching methods probably make math classes attractive in elementary school. Moreover, we did not identify discrepancies between the boys' and girls' responses to questionnaire that sought to verify the feelings about mathematics. The results reflect on the importance of family and teachers to encourage the development of student learning because there are several didactic situations and feelings present in mathematics teaching.

Keywords: Mathematics Teaching, Mathematics Anxiety, Gender, Elementary School.

\section{INTRODUÇÃO}

Os estudos sobre ansiedade à matemática são discutidos pelas comunidades cien-

\footnotetext{
${ }^{1}$ Doutora em Psicologia pela Universidade de Oviedo, professora adjunta da Universidade Federal do Amapá, Departamento de Educação, Curso de Graduação em Pedagogia e professora credenciada no Programa de Pós-Graduação em Educação em Ciências e em Matemática/Rede Amazônica de Educação em Ciências e Matemática, Universidade Federal de Mato Grosso.

${ }^{2}$ Graduada em Pedagoga pela Universidade Federal do Amapá.

3 Doutoranda do Programa de Pós-Graduação em Educação em Ciências e em Matemática/Rede Amazônica de Educação em Ciências e Matemática, Universidade Federal do Mato Grosso e professora adjunta da Universidade Federal do Amapá, Departamento de Educação, Curso de Graduação em Pedagogia.
} 
tíficas, como na área da Psicologia da Educação e Educação Matemática, com intuito de buscar respostas contundentes em relação aos diversos fatores que envolvem a matemática escolar. Assim, as pesquisas corroboram para o melhor entendimento do comportamento ansiogênico tão presente na vida das pessoas.

O primeiro estudo sobre ansiedade foi realizado por Dreger e Aiken (1957). Em seu artigo, os referidos autores a chamaram de "ansiedade numérica". Anos depois, Tobias (1978) substituiu esse termo por "ansiedade à matemática". Outros estudos (FEIO et al, 2008; GEARY, 1996), também foram levados à cabo utilizando o referido termo por se tratar de uma expressão mais condizente com estudantes de diversos níveis de ensino.

Muitos estudantes demonstram insegurança quando se deparam com a matemática escolar. A consequência desse comportamento implica em um distanciamento da disciplina por tratar de inúmeras dificuldades presentes no cotidiano escolar, ou fora dele. Este comportamento é provocado, por vezes, por fatores relacionados à própria metodologia que alguns educadores utilizam para trabalhar a aprendizagem da matemática, o que, provavelmente, contribui, para o aparecimento de um conjunto de reações emocionais negativas como: medo, aversão, fuga, esquiva, conduzindo assim a ansiedade à matemática.

A ansiedade à matemática se caracteriza por um conjunto específico de reações fisiológicas e comportamentais diante de estímulos matemáticos simples ou complexos e diante de contingências de aprendizagem de matemática, ou em contextos que requisitam o uso de repertórios matemáticos (CARMO et al, 2008, p. 192).

Os estudos realizados por Tobias e Weissbrod (1980) a definem como "sensações de pânico, desamparo, paralisia e desorganização mental"; enquanto Richardson e Suinn (1972) indicam "sensações de tensão e ansiedade que interferem na manipulação de números e na solução de situações cotidianas". Na mesma direção, Aschcraft (2002) define ansiedade à matemática como um sentimento de tensão ou medo capaz de interferir no desempenho em matemática.

Neste sentido, múltiplos autores propuseram definições e realizaram estudos sobre o termo ansiedade à matemática. Contudo, Carmo (2003) afirma que cada um enfatiza fatores relevantes, porém não abrangem a totalidade por se tratar de fenômenos ainda em pleno estudo para o entendimento do comportamento humano.

Skinner (1968) ao tratar do ensino escolar, identificou que alguns professores utilizam reforço negativo também chamado de controle aversivo como estratégia para diminuir a frequência de determinados comportamentos.

É comum professores praticarem ou usarem o controle aversivo em sala de aula, para punir ou mesmo manter a ordem e disciplina, na tentativa de garantir bons resultados, entretanto, o uso desta técnica pode provocar sérios problemas na vida de uma criança, a qual responde com comportamentos de fuga e esquiva. Um exemplo de fuga acontece quando o aluno realiza rapidamente uma tarefa de matemática, e um exemplo de esquiva ocorre quando o aluno falta a uma avaliação. São comportamentos gerados 
pela contingência de elementos aversivos.

Para Carmo e Figueiredo (2009) a aversividade não está na matemática, mas nos métodos inadequados que os professores utilizam para ensinar, além da cultura histórica que existe em torno dela. Em outras palavras, em "nossa cultura, tanto a família quanto a escola, e a mídia reforçam a noção de a matemática é ser algo muito difícil, que exige muito esforço para aprender" (CARMO; FIGUEIREDO, 2009, p. 491).

A escola, os professores e a família, em grande medida, reforçam a ideia de que a matemática é algo difícil, sendo quase inevitável que a criança internalize esse conceito e este passe a desacreditar na sua capacidade, o que poderá aumentar a sua ansiedade e insegurança.

Feio et al (2008) nos mostram que é crucial que cada pessoa e instituição assuma seu devido papel na sociedade. Assim, a escola, os professores e a família, se unidos e trabalhando em prol do aluno o estimularia para o melhor desenvolvimento. A família é o primeiro contato da criança na qual ela se desenvolve. Posteriormente, estende-se a escola. Se os mesmos trabalharem juntos se estabelece maior confiança entre pais e professores, o que, provavelmente, incidirá em um conjunto de experiências positivas na vida da criança.

Brito (2002) acrescenta que a confiança em si mesmo, é fator imprescindível na redução da "ansiedade à matemática", pois acredita que a insegurança é a própria ansiedade provocada pela emoção, e descarta o fator intelectual colocando ainda as atitudes como ponto importante no tratamento da ansiedade.

Provavelmente a má formação desses profissionais reflete na escolha de metodologias inadequadas, pois apesar de a matemática ser um curso de licenciatura, é muito frequente o professor formado nesta área não dispor o suficiente, durante a sua formação acadêmica, de disciplinas voltadas para a didática de como desenvolver os conteúdos a serem, ministrados. Também, quando o Curso oferece em sua matriz curricular tal disciplina, torna-se incipiente devido ao pouco interesse nas disciplinas pedagógicas, pois existe a crença de que a disciplina Matemática faz parte do conjunto das disciplinas chamadas "duras".

Pode-se dizer então, que são muitas as causas que produzem ansiedade à matemática. Porém, falhas no ensino podem desencadear aversão nos estudantes, especialmente no que tange a falta de aplicabilidade de métodos e técnicas que facilite o aprendizado do aluno, de modo que torne o ensino atrativo e/ou criem interesse pelo estudo da matemática.

Observa-se que até hoje ainda vigora o modelo tradicionalista de educação, na qual professores insistem em fazer do aluno um mero receptor de conhecimentos, trazendo para salas de aula metodologias coercitivas, obtendo assim, resultados negativos quanto ao desenvolvimento da aprendizagem, realizando suas atividades por pressão e não por prazer.

A motivação é um componente importante que o professor pode lançar mão para estimular os alunos a se interessarem mais pela matemática. Os estudantes são taxados 
como "menos inteligentes" perante a turma, ocasionando desconforto e constrangimento.

Carmo e Figueiredo (2009) encontraram resultados de pesquisas que informam:

Alguns chegam ao cúmulo de afirmar que nem todos nasceram para aprender matemática; matemática é para gênios e os homens são melhores que mulheres em matemática. Essas declarações (regras) podem controlar parte significativa do desempenho de nossos estudantes (CARMO; FIGUEIREDO, 2009, p. 491).

São muitas as práticas coercitivas, por exemplo, pressões impostas, muitas vezes pelos próprios pais, por exigir de seus filhos boas notas e resultados significativos. Peréz (2005) informa que ao invés de incentivá-los, os pais acabam por estimular os filhos a serem matematicamente incapazes, contribuindo para ansiedade extrema em matemática.

Deste modo, pode-se perceber que não existe uma única causa para o insucesso dos alunos no aprendizado da matemática e consequentemente para a ansiedade gerada, mas sim um conjunto de fatores que a envolvem. É importante redefinir as práticas coercitivas, de modo que favoreça o conforto e um aprendizado agradável desta disciplina.

É relevante frisar que ansiedade a matemática não é inata, mas está associada a um conjunto de experiências negativas presenciadas no ambiente escolar, e cobranças impostas pelos pais em casa. Neste sentido, tanto as experiências do âmbito familiar e escolar podem refletir no interesse e aprendizagem de assuntos relacionados com a disciplina de matemática.

Pode-se destacar que nos anos iniciais do Ensino Fundamental há apenas um professor ministrando todas as disciplinas, o que provavelmente aumenta os laços afetivos, visto que nesta fase o professor ao ministrar a disciplina de matemática busca trabalhar a ludicidade por meio de materiais didáticos manipuláveis, como jogos e brincadeiras inseridos na realidade da criança, na qual desperta atenção e interesse do mesmo em aprender matemática. Por outro lado, com o avançar dos anos, a ludicidade encontra-se pouco presente, aumentando a ansiedade e, tornando-se menos atrativo. Sobre este tópico, os resultados dos estudos de Feio et al (2008) mostram que quando os estudantes estão na fase dos anos iniciais, os pais oferecem um apoio maior na vida escolar de seus filhos, quanto as tarefas escolares, mas a medida que vão crescendo, avançando nos anos, o interesse dos pais em oferecer ajuda nas tarefas escolares diminui.

Todavia, Newtead (1998) escreve que a idade entre os nove e onze anos pode ser uma fase crítica para formação das atitudes e emoções para a matemática, pois nessa fase a ansiedade é muito evidente e se não forem moldadas de forma positiva, esta insegurança poderá refletir na sua vida adulta.

Perez (2005) ainda ressalta que o professor deve instigar e questionar seus alunos para despertar a curiosidade e a criticidade na resolução dos exercícios apresentados. 
Outro aspecto a ser considerado, especialmente neste contexto que envolve professores e pais dos alunos, diz respeito à ansiedade estudada em outra perspectiva, por exemplo, gênero e ansiedade à matemática, o que na cultura ocidental abrange a ideia de que os homens são melhores que as mulheres nesta disciplina (FENNEMA, SHERMAN, 1977; 1978).

Em um estudo realizado por Feio et al. (2008) os resultados para a variável gênero mostraram que em muitos aspectos as meninas se destacam mais que os meninos, por outro lado, na dimensão que se referia a "matemática como um campo de meninos", os resultados confirmaram tal hipótese.

Durante muito tempo era perene a percepção de que a matemática não era uma área para mulheres, por se tratar de uma ciência com exigências do raciocínio lógico e dedicação, além de ser base para profissões consideradas pela comunidade verbal, pela sociedade como masculina. Neste complexo arcabouço teórico disponível sobre ansiedade matemática e gênero, é possível encontrar estudos que afirmam que na matemática o desempenho da mulher é inferior ao homem, e neste sentido, o presente trabalho pretende investigar a variável gênero por se tratar de um aspecto importante nas discussões que envolvem a temática da ansiedade à matemática.

\section{METODOLOGIA}

\subsection{Participantes}

Participaram deste estudo duas turmas do 2을 ano do Ensino Fundamental, totalizando vinte e seis estudantes, sendo dezesseis do gênero masculino e dez do gênero feminino, como faixa etária entre seis a nove anos.

Os estudantes foram devidamente autorizados por seus responsáveis para participar do estudo, asssim como foram informados do sigilo em relação as suas identidades, por se tratar de uma pesquisa envolvendo crianças matriculadas em uma escola da rede pública de ensino.

\subsection{Local}

O presente estudo realizou-se, em 2015, na Escola Municipal de Educação Básica Professora Maria IInah de Souza Almeida, localizada no município de Santana, Estado do Amapá, Brasil, nas suas respectivas salas de aulas, no turno vespertino, com autorização do gestor escolar.

2.3 Instrumento de coleta de dados

Aplicou-se um questionário ${ }^{4}$, com oito perguntas, distribuídas da seguinte forma:

\footnotetext{
${ }^{4}$ Adaptação do "Questionário sobre os Sentimentos em relação à Matemática - Smiley-Face Survey", elaborado por Valeski e
} 
1-Você gosta de matemática?;

2- Você se acha um bom aluno em matemática?;

3- Você gosta do seu professor de matemática?;

4- Você gosta das aulas de matemática?;

5-Suas tarefas de matemática são legais?;

6- Como você se sente quando o professor faz uma pergunta de matemática?;

7- Você fica chateado quando erra algum exercício de matemática?;

8- Você fica contente quando você acerta algum exercício de matemática?

Neste questionário, cada pergunta tinha cinco desenhos de carinhas. A primeira representa, quando a criança "não gosta nada de algo ou não está nada contente", a segunda carinha, refere-se quando a criança "não gosta de algo ou não fica contente", já a terceira carinha corresponde "às situações para criança que quando tanto faz" e também "mais ou menos". Por outro lado, a quarta carinha representa quando a criança "gosta de algo ou fica contente" e a última refere-se quando a criança "gosta muito de algo" ou "fica muito contente".

O objetivo é discutir a partir do método estatístico o tema deste artigo, com exposição gráfica dos dados (CRESPO, 2002). Além de diálogar com autores que tratam do assunto deste artigo e sobre os princípios para desenvolver a matemática escolar (HEMBREE, 1990; NEWSTEAD, 1998; CLEMENTS, SARAMA, 2005; NCTM, 2000),

\subsection{Procedimentos}

Primeiramente escolheu-se uma escola da rede municipal para participar da pesquisa. Ao selecionar a escola foram repassadas as instruções, tanto para o corpo técnico, quanto para corpo discente da referida escola. Quanto aos instrumentos de coleta de dados, esclareceu-se que se travava de uma pesquisa, vinculada a UNIFAP, sem objetivo avaliativo e que o preenchimento do questionário deveria ocorrer de forma individual, com sigilo total dos nomes das crianças participantes do estudo para efeitos de comunicação dos resultados.

A coleta dos dados realizou-se na escola no horário vespertino. Um questionário com, contendo as perguntas foi entregue a cada aluno. Em seguida as pesquisadoras explicavam o questionário, ressaltando que deveriam optar apenas por um desenho das carinhas em relação a cada pergunta.

Este desenho representava o sentimento que os participantes atribuíram a resposta, momento em que marcaram um (X), pintar ou desenhar apenas uma das carinhas. Nesta etapa, também foi conferindo item a item das respostas para garantir que nenhuma pergunta do questionário não tivesse resposta.

Stipek (2001) e que também serviu de base para o instrumento de pesquisa de Sun (2009). 


\section{RESULTADO DA PESQUISA}

Os gráficos de linhas, a seguir, sintetizam os aspectos abordados no instrumento de coleta de dados que foi aplicado com as crianças que participaram deste estudo.

Os resultados, conforme o Gráfico 1 indicam que 84,61\% dos estudantes do ensino fundamental gostam muito de matemática. Deste dado quantitativo, $50 \%$ foram as respostas dos meninos e $34,61 \%$ das meninas.

Figura 1 - Você gosta de Matemática? Santana-AP / 2015

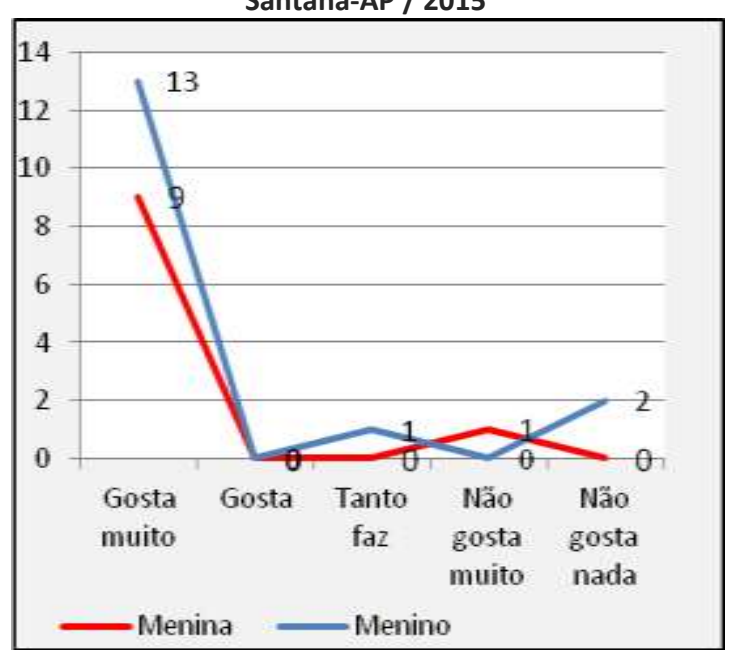

Fonte: Gráfico de linhas elaborado pelas autoras.

Por outro lado, 15,39\% dos estudantes informaram que não gostam, em alguma medida, de matemática. Deste quantitativo, 7,69\% dos estudantes (meninos) responderam que não gostam nada de matemática, enquanto 3,85\% das meninas responderam que não gostam muito, e 3,85\% dos meninos expressaram que tanto faz.

O Gráfico 2 mostra que 76,91\% das crianças responderam que são muito bons estudantes de matemática. Desse total, 30,76\% equivalem as respostas das meninas e $46,15 \%$ dos meninos. Os resultados mostraram que um estudante (menino) se percebe bom aluno em matemática, correspondente a 3,84\%. 
Figura 2 - Você se acha um bom aluno de matemática? Santana-AP / 2015

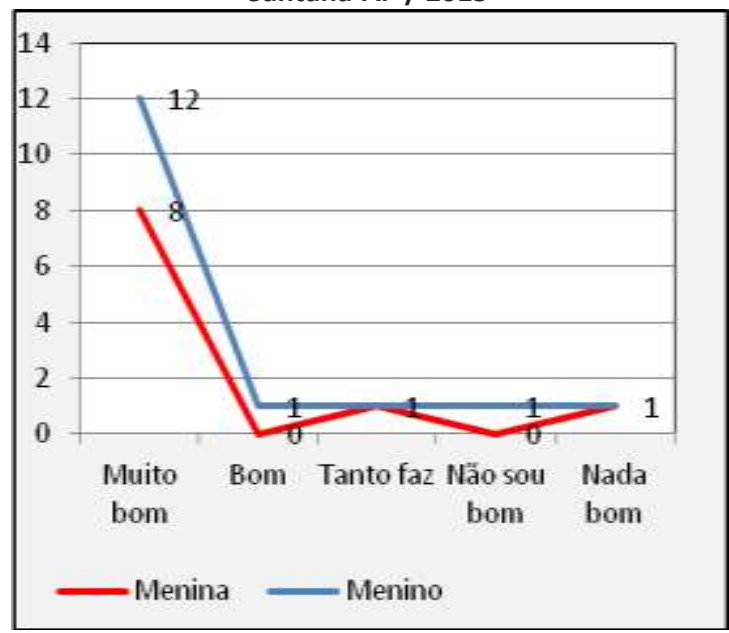

Fonte: Gráfico de linhas elaborado pelas autoras.

Vale mencionar que $7,7 \%$ de meninos e meninas responderam que tanto faz se achar bom aluno de matemática. Além disso, o referido gráfico ainda destaca que somente um menino $(3,85 \%)$ respondeu que não se acha bom em matemática, bem como que $7,7 \%$ expressaram que não se acham nada bons em matemática.

O Gráfico 3 destaca que 38,46\% das meninas expressaram que gostam muito do professor de matemática, bem como $57,69 \%$ dos meninos. Além disso, os dados apresentados nos resultados apontam que $3,85 \%$ do grupo dos meninos não gosta nada do professor de matemática.

Figura 3 - Você gosta do seu professor de matemática? Santana-AP / 2015

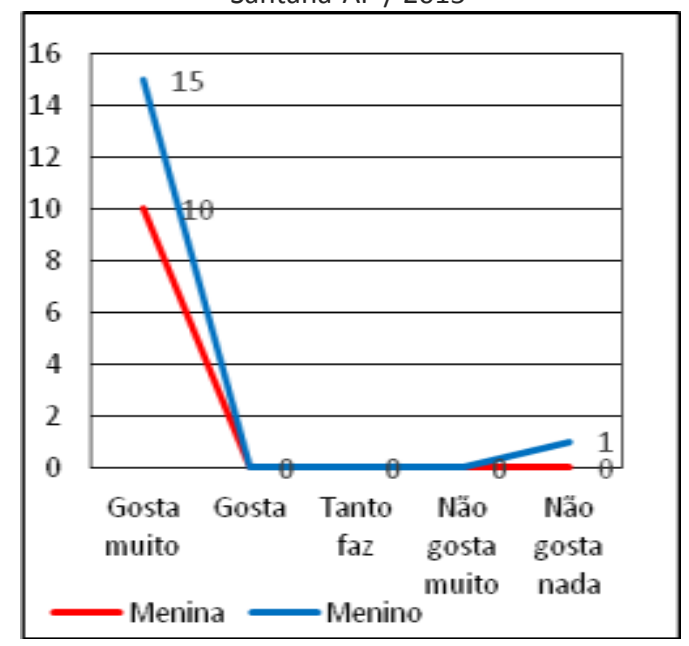

Fonte: Gráficos de linhas elaborados pelas autoras.

Os dados apresentados no Gráfico 4 detalham as respostas dos alunos em relação a quarta pergunta do questionário, em que $26,92 \%$ das meninas responderam que gostam muito das aulas de matemática, enquanto que $11,54 \%$ expressaram que gostam. 
Figura 4- Você gosta das aulas de matemática? Santana-AP / 2015

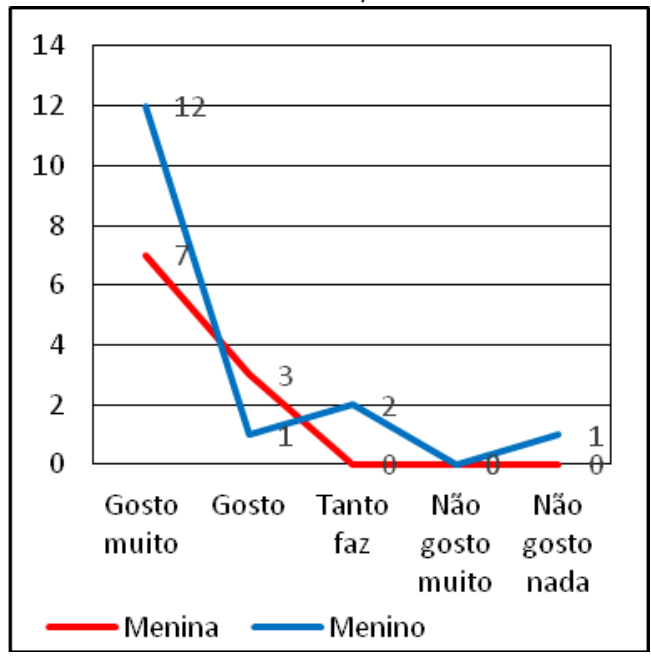

Fonte: Gráfico de linhas elaborado pelas autoras.

Por outro lado, as respostas do grupo dos meninos foram as seguintes, 46,15\% gostam muito, 3,85\% gosta, 7,69\% tanto faz e 3,85\% não gosta nada, o que no Gráfico 4 é apresentado com frequência simples.

Quando questionadas as meninas com relação à pergunta cinco, 30,77\% informaram que as tarefas de matemática "são legais ou muito legais", enquanto os meninos $49,99 \%$.

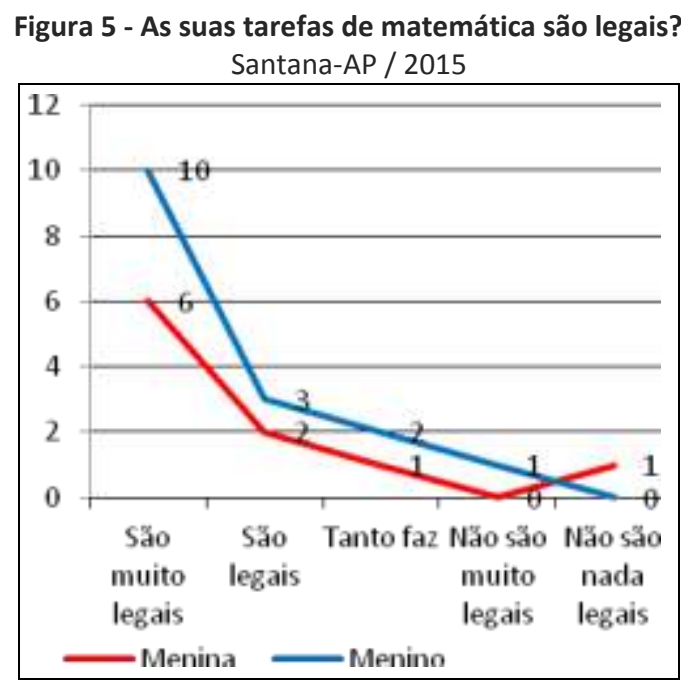

Fonte: Gráfico de linhas elaborado pelas autoras.

Vale mencionar que $3,85 \%$ das meninas disseram que "tanto faz", ser legal ou não as tarefas de matemáticas, enquanto que para os meninos $7,69 \%$. No que diz respeito, as respostas sobre "não achar legal", as tarefas de matemática, tanto meninos (3,85\%), quanto as meninas $(3,85 \%)$ apresentaram o mesmo resultado, perfazendo um total de 7,7\%. Os dados apresentados no Gráfico 6, quando comparados as respostas de meninos e meninas a pergunta seis do questionário, evidenciam que os meninos ficam mais con- 
tentes do que as meninas, no momento em que o professor faz uma pergunta de matemática, o que em frequência relativa equivale, respectivamente, a 38,46\% e 19,22\%.

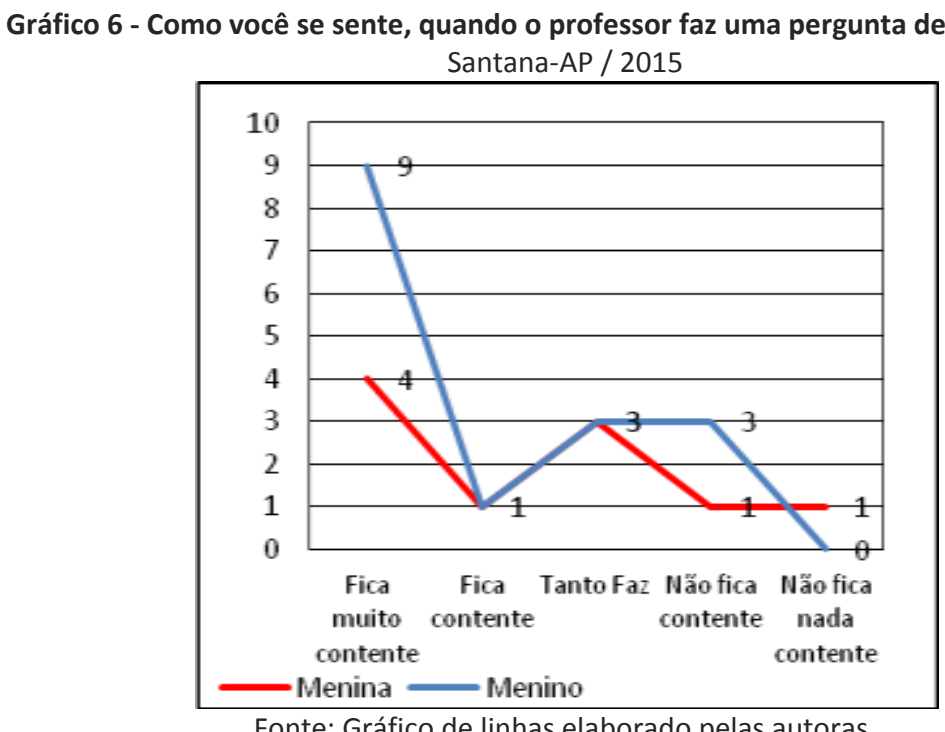

Fonte: Gráfico de linhas elaborado pelas autoras.

Por outro lado, 7,7\% das meninas não ficam contentes, quando o professor faz uma pergunta de matemática, enquanto os meninos $11,54 \%$ informaram o referido sentimento. Ainda sobre pergunta seis, tanto os meninos $(11,54 \%)$ e meninas $(11,54 \%)$ responderam que "tanto faz", o que corresponde a um total de 23,08\%

Os dados do Gráfico 7 revelam que $30,76 \%$ das meninas ficam chateadas, quando erram algum exercício de matemática, enquanto os meninos $42,31 \%$, o que demonstra que os meninos ficam mais chateados que as meninas.

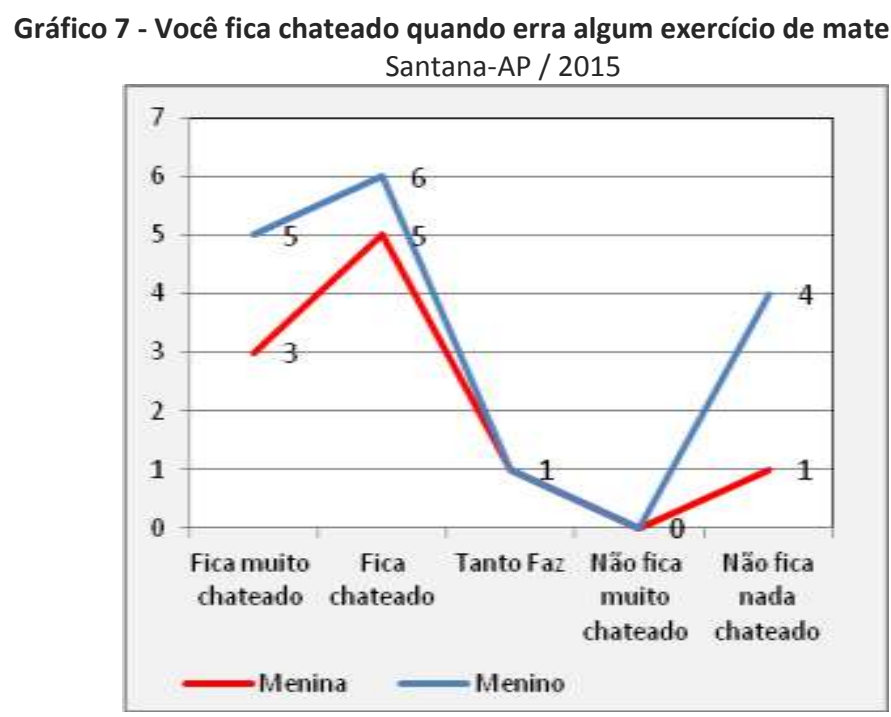

Fonte: Gráfico de linhas elaborado pelas autoras.

Por outro lado, $15,38 \%$ de meninos e 3,85\% de meninas não ficam nada chatea- 
dos quando erram o exercício de matemática. Ademais, 7,7\% de meninas e meninos informaram que "tanto faz" errar um exerício de matemática.

Conforme se observa no Gráfico 8, meninos e meninas ficam muitos contentes, quando acertam os exercícios de matemática, o que equivale a 34,61\% para as meninas e $61,54 \%$ para os meninos.

Gráfico 8 - Você fica contente quando você acerta algum exercício de matemática? Santana-AP / 2015

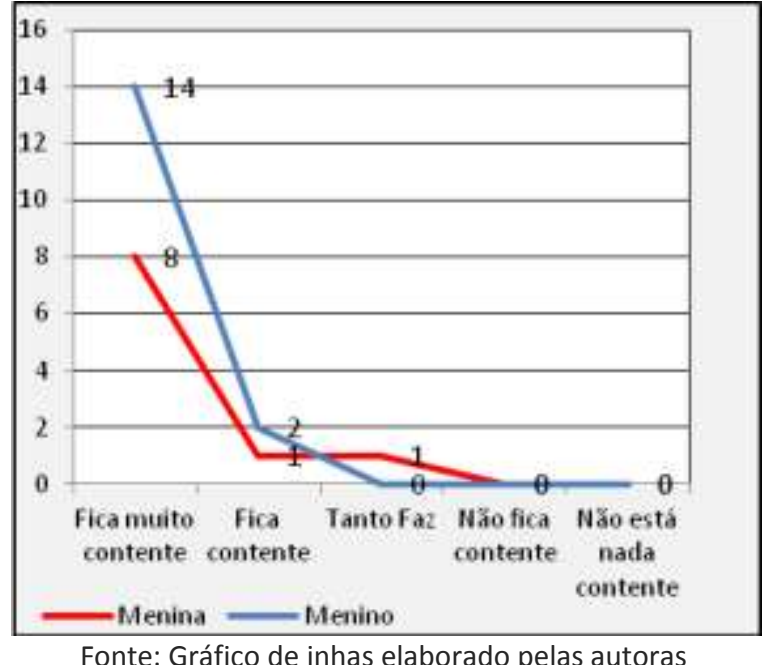

Destaca-se no Gráfico 8 que as crianças ficam contentes quando acertam suas atividades de matemática (96,15\%), inclusive somente 3,85\% das meninas informou que "tanto faz". A pergunta oito mostra que as crianças apresentam sentimentos positivos neste ítem.

Em síntese, os estudantes, do ensino fundamental, segmento I, demonstraram que gostam muito de matemática, em se tratando do ítem 1. As crianças descreveram uma reação positiva para com esta disciplina, perfazendo o equivalente a $84,61 \%$, o que indica sentimentos positivos. O ítem 2 também se destaca, pois a maioria $(80,75 \%)$ das crianças respondeu que se percebem muito bons ou bons estudantes de matemática. Os dados que mostraram sentimentos muito positivos para com as matemáticas foram os relacionados aos ítens 3 e 8 , em que 96,15\% das crianças informaram que gostam muito de seus professores de matemática; e o mesmo percentual foi achado quando as crianças informaram que ficam contentes quando acertam os exercícios de matemática. De todas as perguntas elencadas no questionário, estas duas foram as de maiores destaques, alcançando os índices mais altos de sentimentos positivos ante as matemáticas, perfezendo um total de $96,15 \%$ para cada uma.

Depreende-se que quando os estudantes acertam suas atividades, os mesmos se sentem felizes e, provavelmente, cultivam sentimentos positivos por esta disciplina tão relevante, mas que, por vezes, tais estudantes não veem sua utilidade, e apresentam comportamentos ansiogênicos nesta matéria. No item 8 (Você fica contente quando você acerta algum exercício de matemática?) os meninos se destacaram com $61,54 \%$ de- 
monstrando sentimentos positivos quando acertam. Os resultados indicaram também que $88,46 \%$ das crianças informaram que gostavam das aulas de matemática e $80,77 \%$ achavam que as tarefas de matemática eram legais.

Outro achado interessante diz respeito à pergunta seis do questionário. Os dados apontam que este ítem descreveu uma reação negativa muito forte, produzindo o índice mais baixo de sentimentos positivos quando o professor faz uma pergunta de matemática ao aluno, pois os demais dados apresentam uma média acima de $80 \%$ no que diz respeito a sentimentos positivos ante as matemáticas. Parece que as crianças sentem um desconforto quando o professor de matemática lhe faz alguma pergunta, pois, 42,32\% das crianças não ficam contentes, quando o professor faz uma pergunta de matemática. Apesar de este dado apresentar o índice bastante negativo em relação aos demais sentimentos das crianças para com as matemáticas, os meninos informaram que ficam mais contentes do que as meninas no momento em que o professor faz uma pergunta de matemática.

O item que descreveu uma reação negativa muito forte foi o item 7, com $73,07 \%$ do total de crianças, indicando que elas ficavam chateadas quando erravam algum exercício de matemática.

Finalizando, ser menino ou menina, no ensino fundamental, segmento 1 , não altera a percepção quanto aos sentimentos na disciplina de Matemática, pois, as crianças apresentaram sentimentos bastantes positivos em relação a esta disciplina. Os meninos apresentaram sentimentos, discretamente, mais positivos para com as matemáticas, quando comparados às meninas.

\section{DISCUSSÃO}

O resultado da pesquisa indica que crianças, na faixa etária entre seis e nove anos, não apresentam ansiedade a matemática, o que é possível observar em todos os resultados, quando as crianças demonstram sentimentos bastante positivos para com a matemática. Neste sentido, é crucial que os professores busquem metodologias para aprimorar aprendizado dos estudantes do ensino fundamental em matemática.

É muito frequente os professores utilizarem reforços negativos para punir ou mesmo manter a disciplina em sala de aula, porém, esses métodos aversivos podem intimidar a criança e, consequentemente, ela responder com comportamento de fuga e esquiva.

Estudos realizados por Hembree (1990) e Newstead (1998) mostraram que as crianças parecem desenvolver ansiedade à matemática com idade precoce, ainda na educação infantil e nos primeiros anos do ensino fundamental. Tais resultados discrepam dos resultados do presente estudo, considerando que os estudantes do ensino fundamental, com faixa etária entre seis e nove anos, não manifestaram ansidedade a matemática ao responder o instrumento desta pesquisa.

As crianças devem estar em um ambiente rico e significativo para estudar (CLE- 
MENTS, SARAMA, 2005; NCTM, 2000), com fim de construir seus conhecimentos da disciplina de Matemática ou desenvolver a Matemática Escolar, especialmente nos primeiros anos. Assim, nesta fase da vida escolar é essencial concentrar esforços para instigar novas metodologias de ensino, com base em princípios que estimulem o ensino e aprendizagem dos conteúdos matemáticos.

Neste sentido, a reflexão e a auto avaliação acerca da prática docente atuante e reflexiva é fundamental, como por exemplo, conhecer a realidade econômica e social dos seus alunos, resgatar a importância da matemática, estabelecer a relação da matemática aplicada em sala de aula com a realidade dos estudantes; ajudá-los a superar suas dificuldades, valorizar seus conhecimentos prévios com relação à disciplina e considerar a cultura do estudante.

\section{CONSIDERAÇÕES FINAIS}

$\mathrm{O}$ artigo discute ansiedade à matemática com estudantes do $2^{\circ}$ ano do Ensino Fundamental, enfocando dois objetivos. O primeiro permitiu identificar que $84.61 \%$ do estudantes não manifestaram ter ansiedade à matemática. Mas deste quantitativo, 50\% dos meninos responderam de gostam muito de matemática e apenas $34,61 \%$ das meninas responderam o mesmo.

Também foi possível comparar as respostas de meninos e meninas, no que tange a ansiedade à matemática, cujos dados apontaram que 7,69\%, dos meninos não gostam nada de matemática e nenhuma menina escolheu o desenho da carinha que representava a resposta "não gosta nada".

Os resultados não mostram discrepância quanto ao sentimento de aversão a matemática ou as crianças não expressaram ter ansiedade, quando envolve questões relacionadas à matemática, conforme verificado pelas respostas de $7,7 \%$ dos estudantes da escola pública.

Este trabalho também tem suas limitações, já que não tivemos a finalidade de esgotar o debate com relação à Ansiedade a Matemática e Gênero, mas contribuir com as pesquisas em Psicologia ou Educação Matemática, e ainda, em longo prazo, estimular a realização de outros estudos.

A realização da pesquisa propiciou uma visão mais ampla sobre a importância da família e dos professores incentivarem o desenvolvimento da aprendizagem dos estudantes, pois são muitas as situações didáticas que envolvem o conhecimento matemático.

\section{REFERÊNCIAS}

ASHCRAFT, M. H. Math anxiety: Personal, educational, and cognitive consequences.

Current Directions in Psychological Science, California, v. 11, n. 5, p. 181-185, 2002.

BRITO, M. R. F. Atitudes, ansiedade, afeto e Matemática. In: Anais do XIX Encontro Na- 
cional de Professores do PROEPRE. Campinas: FE, 2002. v. 1, p. 81-93.

CARMO, J. S. Ansiedade matemática: conceituação e estratégias de intervenção. In: M.

Z. S. Brandão et al (Org.). Sobre comportamento e cognição: a história e os avanços, a seleção por conseqüência em ação. Santo André: ESETec, 2003. v. 11. p. 433-442.

.; CUNHA, L. O; ARAUJO, P. V. S. Análise comportamental da ansiedade à matemática: conceituação e estratégias de intervenção. In: Da SILVA, W.C.M.P. (Org.). Sobre comportamento e cognição. Santo André: ESETec; Ed. Associados, 2008. p. 185-195.

; FIGUEIREDO, R. M. E. Ansiedade à matemática em alunos do Ensino Fundamental: achados recentes e implicações educacionais. In: WIELENSKA, R. C. (Org.). Sobre comportamento e cognição: aspectos teóricos, metodológicos e de formação em análise do comportamento e terapia cognitivista. Santo André: ESETec; 2009. p. 488-495.

CLEMENTS, D. H.; SARAMA, J. Math play: How young children approach math. Scholastic Early Childhood Today, Nova York, v. 19, n. 4, p. 50-57, 2005.

CRESPO, A. A. Estatística Fácil. 18.ed. São Paulo: Saraiva, 2002.

DREGER, R. M.; AIKEN JR., L. R. The identification of number anxiety in a college population. Journal of Educational Psychology, Washington, v. 48, n. 6, p. 344-351, 1957.

FEIO, L. S. R. Variables cognitivo-motivacionales, comportamentales y contextuales y su relación con los procesos de autorregulación en el área de las matemáticas. Universidad de Oviedo. Oviedo, 2008.

FEIO, L. S. R. et al. Implicación familiar percibida, actitudes hacia las matemáticas y rendimiento académico. In: SILVA, W. C. M. P. (Org.). Sobre Comportamento e Cognição. Santo André: ESETec, 2008, v. 21, p. 209-218.

FENNEMA, E; SHERMAN, J. A. Sex-related differences in mathematics achievement, spatial visualization, and affective factors. American Educational Research Journal Washington, v. 14, n. 1, p. 51-71, 1977.

;__. Sex-related differences in mathematics achievement and related factors: A further study. Journal for Research in Mathematics Education, Reston, v. 9, n. 3, p. 189203, 1978.

FERRANTI, M. C. Implicación familiar percebida, actitudes hacia las matemáticas y rendimiento acadêmico. In: SILVA, W. C.M. P. (Org.). Sobre comportamento e cognição: análise comportamental aplicada. Santo André: ESETec; Ed. Associados, 2008. v. 21. p. 209-218.

GEARY, D. C. Children's mathematical development: research and practical applications. Washington: American Psychological Association, 1996.

HEMBREE, R. The nature, effects, and relief of mathematics anxiety. Journal for Research in Mathematics Education, Reston, v. 21, n. 1, p. 33-46, 1990. 
NATIONAL COUNCIL FOR TEACHERS OF MATHEMATICS. Curriculum and evaluation standards for school mathematics. Reston: VA, 2000.

NEWSTEAD, K. Aspects of children's mathematics anxiety, Educational Studies in Mathematics, Netherlands, v. 36, n. 1, p. 53-71, 1998.

PÉREZ, A. I. The impact of mathematics anxiety, gender, and mathematics achievement on ontogenetic indicators for hispanic/latino students in higher education mathematics classes. (Doctoral Thesis). Texas: Texas A \& M University, 2005.

RICHARDSON, F. C.; SUINN, R. M. The mathematics anxiety rating scale: Psychometric data. Journal of Counseling Psychology, Washington, v. 19, n. 6, p. 551-554, 1972.

SHERMAN, J. A; FENNEMA, E. The study of mathematics by high school girls and boys: Related variables. American Educational Research Journal, Washington, v. 14, n. 2, p. 159-168, 1977.

SKINNER, B. F. The Technology of Teaching. New York: Appleton-Century-Crofts, 1968.

SUN, H. Investigating feelings towards mathematics among chinese kindergarten children. In: HUNTER, R.; BICKNELL, B.; BURGESS, T. (Ed.). Proceedings of 32nd Annual Conference of the Mathematics Education Research Group of Australasia. Wellington: Merga Inc., 2009.

TOBIAS, S. Overcoming math anxiety. New York: Norton, 1978.

.; WEISSBROD, C. Anxiety and mathematics: an update. Harvard Educational Review, Cambridge, v. 50, n. 1, p. 63-70, 1980.

VALESKI, T. N., STIPEK, D. J. Young children's feelings about school. Child Development, Hoboken, v. 72, n. 4, p. 1198-1213, Jul./Aug. 2001.

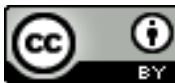
Creative Commons Attribution License, which permits unrestricted use, distribution, and reproduction in any medium, provided the original work is properly cited.

Article received on January 19, 2018.

Accepted on December 26, 2018. 